\title{
"Tertius gaudens": germplasm exchange networks and agroecological knowledge among home gardeners in the Iberian Peninsula
}

\author{
Victoria Reyes-García 1,2, José Luis Molina², Laura Calvet-Mir ${ }^{3}$, Laura Aceituno-Mata4 , Juan J Lastra5, \\ Ricardo Ontillera ${ }^{4}$, Montse Parada ${ }^{6}$, Manuel Pardo-de-Santayana ${ }^{4}$, Montse Rigat ${ }^{6}$, Joan Vallès ${ }^{6}$ and Teresa Garnatje ${ }^{7 *}$
}

\begin{abstract}
Background: The idea that knowledge flows through social networks is implicit in research on traditional knowledge, but researchers have paid scant attention to the role of social networks in shaping its distribution. We bridge those two bodies of research and investigate a) the structure of network of exchange of plant propagation material (germplasm) and b) the relation between a person's centrality in such network and his/her agroecological knowledge.
\end{abstract}

Methods: We study 10 networks of germplasm exchange $(n=363)$ in mountain regions of the Iberian Peninsula. Data were collected through participant observation, semi-structured interviews, and a survey.

Results: The networks display some structural characteristics (i.e., decentralization, presence of external actors) that could enhance the flow of knowledge and germplasm but also some characteristics that do not favor such flow (i.e., low density and fragmentation). We also find that a measure that captures the number of contacts of an individual in the germplasm exchange network is associated with the person's agroecological knowledge.

Conclusion: Our findings highlight the importance of social relations in the construction of traditional knowledge.

Keywords: Home gardens, Ethnobotany, Germplasm exchange, In situ conservation, Landraces, Social network analysis, Spain, Traditional ecological knowledge

\section{Background}

Local communities often possess a detailed knowledge of their resources $[1,2]$ that potentially provides a valuable management base $[3,4]$ and a source of resilience to deal with change [5]. Because of the potential of traditional ecological knowledge, sensu Berkes et al. [6], and associated practices to sustain the natural base for livelihoods, researchers have tried to understand the pathways for the acquisition, maintenance, erosion, and spread of this type of knowledge. Previous research has noticed that traditional ecological knowledge is not uniformly distributed among resource users, and consequently, researchers have studied the sociodemographic characteristics that pattern intracultural distribution of knowledge. Researchers have found that age, sex, education, kinship, place of residency,

\footnotetext{
* Correspondence: tgarnatje@ibb.csic.es

IInstitut Botànic de Barcelona (IBB-CSIC-ICUB), Passeig del Migdia s.n., Parc de Montjuïc, 08038, Barcelona, Catalonia, Spain

Full list of author information is available at the end of the article
}

social status, level of acculturation, and level of integration into the market economy, among others, correlate with intracultural variation in traditional ecological knowledge [7-10].

Researchers have based the systematic analysis of the pathways through which traditional ecological knowledge is transmitted on the seminal work of Cavalli-Sforza and colleagues [11]. Based on generational differences and social relations between actors, this work considers three main pathways for the transmission of cultural knowledge: 1) vertical transmission, when information flows across individuals from different generations related through kinship [11,12], 2) horizontal transmission, when information is transmitted between any two individuals of the same generation [13], and 3) oblique transmission, when information flows across individuals from different generations but not related through kinship [11,14]. Recent research shows that the influence of each pathway changes across a person's lifecycle [15].

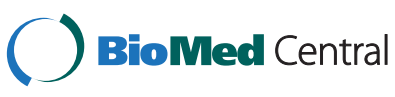


While the idea that cultural knowledge flows through social relations is implicit in this line of thought, researchers have not engaged in a systematic analysis of the relations between the structure of social networks and the distribution of traditional ecological knowledge. This research gap is especially surprising given the well established finding from research on social networks highlighting that a node's position in the network is a measure of the degree and type of information the node holds [12-14]. For example, in organizational settings, Brass and Burkhardt [15] have shown that the ability of a firm to capture knowledge is influenced by the position of the firm in the network. Similarly, Burt [12] shows how structural holes, i.e., the ability of an individual to bridge the gap among otherwise disconnected social groupings, bring new ideas to individuals because of their ability for assessing and comparing the different social groupings in which they are active.

The scant systematic research on the role of social relations on the transmission of traditional ecological knowledge has highlighted that information sharing among resource managers is based on trust and mostly occurs through kinship, friendship [16], or other social relations such as occupation [17] or ethnic background [18]. But we know little about how structural characteristics that have proven central in the transmission of other types of information affect the transmission of traditional ecological knowledge. In this article we bridge research on the distribution of traditional ecological knowledge and research on social networks to investigate the relation between a person's position in a network and her/his agroecological knowledge. We start by analyzing the structure of plant propagation material exchange networks and we then assess the association between a gardeners' centrality in such networks and their agroecological knowledge. Research was conducted among home garden tenders in mountain regions of the Iberian Peninsula.

Our study focuses on networks of exchange of plant propagation material, mainly seeds, but also seedlings, bulbs, tubers, cuttings, suckers (hereafter germplasm exchange networks). We studied home gardens because they are considered in situ repositories of genetic diversity [19] and legacies of traditional gardening practices. Furthermore, both germplasm and knowledge are transmitted over generations [20,21].

Based on Berkes et al. [6] and Armitage [22], we use the term "agroecological knowledge" to refer to the cumulative body of knowledges, practices, and beliefs related to agronomic practices evolving by adaptive processes and handed down through generations by cultural transmission. We follow Calvet-Mir et al. [23] and use the term "landrace" to refer to annual and biennial crops that have been continuously reproduced by gardeners during more than one generation (30 years or more, or 60 in the case of perennial crops and crops with vegetative reproduction) in the geographic area of study.

Researchers have previously described networks of germplasm exchange in different landscapes and socioeconomic conditions [24] highlighting the contribution of those exchanges to the conservation of agrobiodiversity in farmers' fields [25-28]. For example, Boster [7] analyzed the social processes through which manioc (Manihot esculenta Crantz) stem cuttings are transmitted, sustained, and enhanced through networks of female linked by kinship ties; in a study in Peru, Ban and Coomes [26] found that home gardens agrobiodiversity is strongly tied to the number of seedlings and seed exchanges done by the gardeners; and Ellen and Platten [29] described germplasm circulation (or "the social life of seeds") in British allotments. But, with some exceptions (see [30,31]), those studies have not analyzed the link between the person's structural position in the germplasm exchange network and his/her agroecological knowledge.

\section{Methods \\ Study sites}

We used a multicommunity approach and analyzed 10 independent networks placed in the Catalan Pyrenees (5), central Asturias (1), and Sierra Norte, Madrid (4). The three areas are in mountain regions, where the prevalence of slopes makes intensive agriculture difficult. Despite their linguistic and cultural differences since the 1960s, the three areas have suffered similar changes in the commercial agricultural sector resulting either in the concentration of agricultural activities in the more productive lands or in their abandonment by shifting to other activities (mining, construction, services) [32]. However, in the three areas home gardens persist nowadays as the most characteristic and widespread form of agriculture $[23,33,34]$ providing a non-negligible financial gross value as well as social benefits $[35,36]$.

\section{Sample}

Our sampling strategy proceeded in two steps. On the first scooping step, we selected a range of villages representing the environmental and socioeconomic variability of the areas and interviewed between $20 \%$ and $100 \%$ of the households (depending on the total number of active home gardens) [36]. This preliminary work served us to identify 10 germplasm exchange networks, defined as a group of gardeners potentially related by the exchange of seeds or other plant propagation material. On the second step, we interviewed all the primary tenders (i.e., the person who reportedly made most of the decisions and carried out most of the work on the home garden) in the 10 selected networks. Our total sample includes 363 individuals in 10 independent networks across the three study areas: eight of the networks correspond to villages 
and two (Vall Fosca and Valle del Cordal) to valleys with several small villages closely related one to each other (see Table 1 for a breakdown of the sample site by network).

\section{Methods of data collection}

A multidisciplinary team of social and natural scientists collected data during April 2008-October 2009 using participant observation, semi-structured interviews, garden inventories, and a survey.

\section{Participant observation}

Six researchers had a continuous presence in the study sites for about a year (some of them are residents to the study areas). The rest of the team conducted shorter visits to some of the sites. Participant observation allowed the understanding of the different activities and tasks around gardening by giving us ample opportunities -other than during the formal interviews- to interact with gardeners and to discuss garden's progress and other issues. The results of the ethnographic research have been presented in previous works [33-35,37].

\section{Semi-structured interviews}

We also carried out semi-structured interviews with more than 90 'local experts' (about 30 per study area), defined here as local inhabitants with long-term experience with traditional management of home gardens in the area [38]. During semi-structured interviews we asked about the practice of exchanging seeds and other germplasm and its purpose, persistence, and usefulness. We also discussed traditional management of home gardens and changes on management techniques over the last decades.

\section{Garden inventories}

We visited each garden in the sample and requested the self-reported main tender to accompany us. We asked the tender to identify all the cultivated plants present in the garden. We took a picture and recorded the local name and the main use (i.e., edible, medicinal, ornamental) of each species. We noted the species that matched our definition of landrace. We determined the species (scientific names) mainly in the field, but we took vouchers of species that could not be easily identified in the field for laboratory identification. Vouchers have been deposited in the herbarium of the Centre de Documentació de Biodiversitat Vegetal, Universitat de Barcelona $(\mathrm{BCN})$, in the herbarium of the Departamento de Biología de Organismos y Sistemas, Universidad de Oviedo (FCO), or in the herbarium of the Real Jardín Botánico, CSIC, in Madrid (MA).

\section{Survey}

We based the construction of the survey in information collected with participant observation, semi-structured interviews, and garden inventory. We conducted a survey with all the primary garden keepers. The survey had three sections. In the first section, we asked about sociodemographic characteristics of the person answering the survey (age, sex, maximum education level, years gardening, and length of residency). In the second section, we asked gardeners about their germplasm exchange network using a name-generator technique [39]. Specifically, we asked, "Could you please list the name of all the people to whom you have ever given seeds or any other type of propagule?" Once the person stopped providing names, we asked "Could you please list the name of all the people who has ever given you seeds or any other type of propagule?" For each name listed, we also asked the respondent to provide the place of residence.

To evaluate gardeners' agroecological knowledge, the last section of the survey consisted of a knowledge test. Because species and practices vary from one site to

Table 1 Structure of ten seed exchange networks in the Iberian Peninsula

\begin{tabular}{|c|c|c|c|c|c|}
\hline & & [1] & [2] & [3] & [4] \\
\hline Area & Network name (n) & \# Nodes^ (Gardeners) & Density & Components & Network centralization (\%) \\
\hline Asturias & Valle del Cordal $(n=56)$ & $118(=40+56+22)$ & 0.017 & 6 & 8.09 \\
\hline \multirow[t]{5}{*}{ Catalan Pyrenees } & Llanars $(n=21)$ & $50(=0+21+29)$ & 0.019 & $15^{*}$ & 6.68 \\
\hline & Llançà ( $n=15)$ & $24(=5+15+4)$ & 0.052 & 11 & 21.54 \\
\hline & Maçanet de Cabrenys $(n=31)$ & $34(=0+31+3)$ & 0.043 & $14^{*}$ & 12.69 \\
\hline & Molló ( $n=34)$ & $42(=0+34+8)$ & 0.023 & $16^{*}$ & 7.99 \\
\hline & Vall Fosca $(n=55)$ & $111(=14+55+42)$ & 0.018 & 5 & 4.91 \\
\hline \multirow[t]{4}{*}{ Sierra Norte de Madrid } & Canencia ( $n=23)$ & $33(=0+23+10)$ & 0.037 & 7 & 6.94 \\
\hline & Montejo de la Sierra $(n=27)$ & $65(=16+27+22)$ & 0.032 & 3 & 16.39 \\
\hline & Patones $(n=40)$ & $114(=15+40+59)$ & 0.025 & 7 & 12.01 \\
\hline & Valdemanco $(n=61)$ & $108(=22+61+25)$ & 0.020 & 4 & 7.14 \\
\hline
\end{tabular}

$\wedge$ \# Nodes or Gardeners = (Nodes outside research area + nodes with complete data for multivariate analysis + nodes with incomplete data or not interviewed). * Less than $50 \%$ of the nodes belong to the main network. 
another, we constructed site-specific knowledge tests (i.e., we used 10 different tests, one for each site). To ensure comparability of results across sites, we constructed the 10 tests following the same protocol and with the same structure, in each case using information from semistructured interviews and garden inventories.

Our knowledge tests included a section on landraces and a section on traditional management practices. To capture variability in knowledge and to keep the survey in a reasonable length, we used information from garden inventories (i.e., frequency of appearance) participant observations to select one well known, one relatively known, and one rare landrace in each site. For each landrace we requested gardeners a) to provide the folk name of the species (by identifying seeds and pictures) (SpName), to report whether they b) were growing the landrace at the time of the interview (SpPlant), c) had grown it during previous years (SpPlantPast), d) had it in storage (SpSeed), and e) to answer a question on landrace management (SpManag) and f) a question on landrace use (SpConsum). The section on traditional management practices included questions on whether the gardener had ever applied specific traditional management practices in the garden (TradManagPast) and four questions on whether the gardener used the same practices at the moment of the interview (TradManagNow). Questions on landrace management and use and questions on the traditional management practices were selected from information collected during semi-structured interviews with locally recognized experts. Table 2 presents one of the knowledge test used as an example.

\section{Methods of data analysis Social network analysis}

We used social network analysis a) to examine the structure of the germplasm exchange networks and b) to generate two variables that capture the structural position of an individual in the network [40-42]. Information was treated with UCInet6-Netdraw for Windows [43]. To explore the structure of the network of plant propagation exchange, we first added information on nominations as seed givers and seed receivers. Adding the two matrices we obtain a single enlarged matrix with the value " 2 " in the cells corresponding to reciprocal nominations (A mentions $\mathrm{B}$ as exchange partner and $\mathrm{B}$ mentions A as exchange partner as well), the value " 1 " for nonreciprocal nominations, and " 0 " for the rest (see [30] for a detailed explanation).

We then calculated four measures that describe the structure of a network: 1) Size, or number of gardeners (nodes) in the network, including gardeners in the research areas and gardeners outside them; 2) Number of components or connected sub-networks in which all gardeners are directly or indirectly in contact with each other; 3) Density or the proportion of existing links in the network relative to the maximum possible number of links (from 0 to 1); and 4) Network centralization or the tendency for a few gardeners to concentrate the existing links (expressed as a percentage).

We used the same data to generate two different variables that capture the structural position of an individual in the network: 1) Weighted degree or the sum of the number of nominations that a gardener received on other's lists plus the number of nominations that the gardener made, and 2) Broker or the number of times a gardener (ego) lies on the shortest path between two other gardeners (alters) not connected among them. This variable captures the contribution of a gardener to minimize the distance between gardeners in the germplasm exchange network [43].

\section{Construction of outcome variables}

A person's agroecological knowledge score was constructed using answers to the questions on the knowledge test, with a range from 0 to 26 . We added a point to the agroecological knowledge score if the informant a) was able to provide the folk name of the landrace, b) was growing the landrace at the time of the interview, c) had grown the landrace during previous years, d) or had the landrace in storage. We added additional points if answers to questions on landrace management and use matched the information provided by local experts during semistructured interviews. Last, we also added points to the score of agroecological knowledge for each of the traditional management practices the gardener reportedly applied (in the past or nowadays). Surveys were pretested with gardeners outside our sample.

\section{Statistical analysis}

To estimate the association between a person's agroecological knowledge and structural position in the germplasm exchange network, we ran a Poisson multivariate regression with (a) agroecological knowledge as outcome variable and (b) our two centrality measures (degree and broker) as explanatory variables while controlling for additional factors that research suggest affect the distribution of traditional ecological knowledge (i.e., age, sex, years gardening, schooling, and years of residency). Because networks vary in structure, before conducting the analysis, we normalized the two measures (by dividing by the mean) and used the normalized version. For the statistical analysis we used STATA 9 for Windows.

\section{Results}

\section{Structure of the germplasm exchange networks}

Germplasm exchange networks varied in the number of gardeners that composed them (from 24 to 118) and in the proportion of gardeners from outside the research 
Table 2 Example of knowledge test (from the Llançà network)

\begin{tabular}{|c|c|c|c|}
\hline Alone & Did the person answer all the survey without help & YES & NO \\
\hline Traditional common & Brassica oleracea var. oleracea & & \\
\hline Sp1Name & What is the name of this plant? & (text) & \\
\hline Sp1Plant & Have you planted it in your garden this year? & YES & nO \\
\hline Sp1Plantpast & Have you planted it in previous years? & YES & NO \\
\hline Sp1Seed & Did you keep seeds from last year? & YES & nO \\
\hline Sp1Manag & What is the best moment to plant this species? & (text) & \\
\hline Sp1Consum & How do you know when is ready for human consumption? & (text) & \\
\hline Traditional intermediate & Brassica napus & & \\
\hline Sp2Name & What is the name of this plant? & (text) & \\
\hline Sp2Plant & Have you planted it in your garden this year? & YES & NO \\
\hline Sp2Plantpast & Have you planted it in previous years? & YES & nO \\
\hline Sp2Seed & Did you keep seeds from last year? & YES & NO \\
\hline Sp2Maneg & What is the best moment to plant this species? & (text) & \\
\hline Sp2Consum & How do you know when is ready for human consumption? & (text) & \\
\hline Traditional rare & Cynara cardunculus & & \\
\hline Sp3Name & What is the name of this plant? & (text) & \\
\hline Sp3Plant & Have you planted it in your garden this year? & YES & NO \\
\hline Sp3Plantpast & Have you planted it in previous years? & YES & NO \\
\hline Sp3Seed & Do you try to keep it in your garden? & YES & NO \\
\hline Sp3Maneg & What is the edible part? & (text) & \\
\hline Sp3Consum & What are its uses? & (text) & \\
\hline \multicolumn{4}{|l|}{ Management } \\
\hline TradManag1Now & Do you use moon cycles to plant? & YES & NO \\
\hline TradManag1Past & Did you use to do it before? & YES & NO \\
\hline TradManag2Now & Have you done tomatoes preserves this year? & YES & NO \\
\hline TradManag2Past & Did you use to do it before? & YES & NO \\
\hline TradManag3Now & Do you prepare a seedbed of this plant? & YES & nO \\
\hline TradManag3Past & Did you use to do it before? & YES & NO \\
\hline TradManag4Now & Do you put ashes in the place prepared to plant garlic and onions? & YES & NO \\
\hline TradManag4Past & Did you use to do it before? & YES & NO \\
\hline
\end{tabular}

area (Table 1, Figure 1). Overall, the studied networks have low densities (Column 2) and are highly fragmented, i.e., have several sub-networks (Column 3). From a range from 0 to 1 , the highest density level was around 0.05 , indicating that there are few ties even between the gardeners that are actually connected on the same network.

Our data also suggest that gardeners that could potentially belong to a simgle germplasm exchange network were in fact organized in smaller groups. All the networks analyzed but two have five or more components or sub-networks, meaning that gardeners were actually organized in several disconnected networks (Column 3). Four networks had more than 10 sub-networks and one had as much as 16 (most of them isolated gardeners with no exchanges within the network). In three of the 10 networks, the largest component contains less than
$50 \%$ of the gardeners that could potentially be linked. The network centralization indexes are also low (Column 4). Relative to a pure star network, where a single gardener would hold all connections to the rest (otherwise unconnected) gardeners, only four of the networks analyzed had a centralization index higher than $10 \%$, and only one had a centralization index higher than $20 \%$.

\section{Agroecological knowledge and network centrality}

The average agroecological knowledge is close to the medium value (13), but displays large variation among people in the sample (mean $=13.7 ; \mathrm{SD}=5.37$ ) (Table 3). The average values for the variables that measure degree were low $(\operatorname{mean}=4.77 ; \mathrm{SD}=4.26 ; \min =0 ; \max =30)$, meaning that -on average- each person gave or received seeds and other propagules from 4.77 different people. 


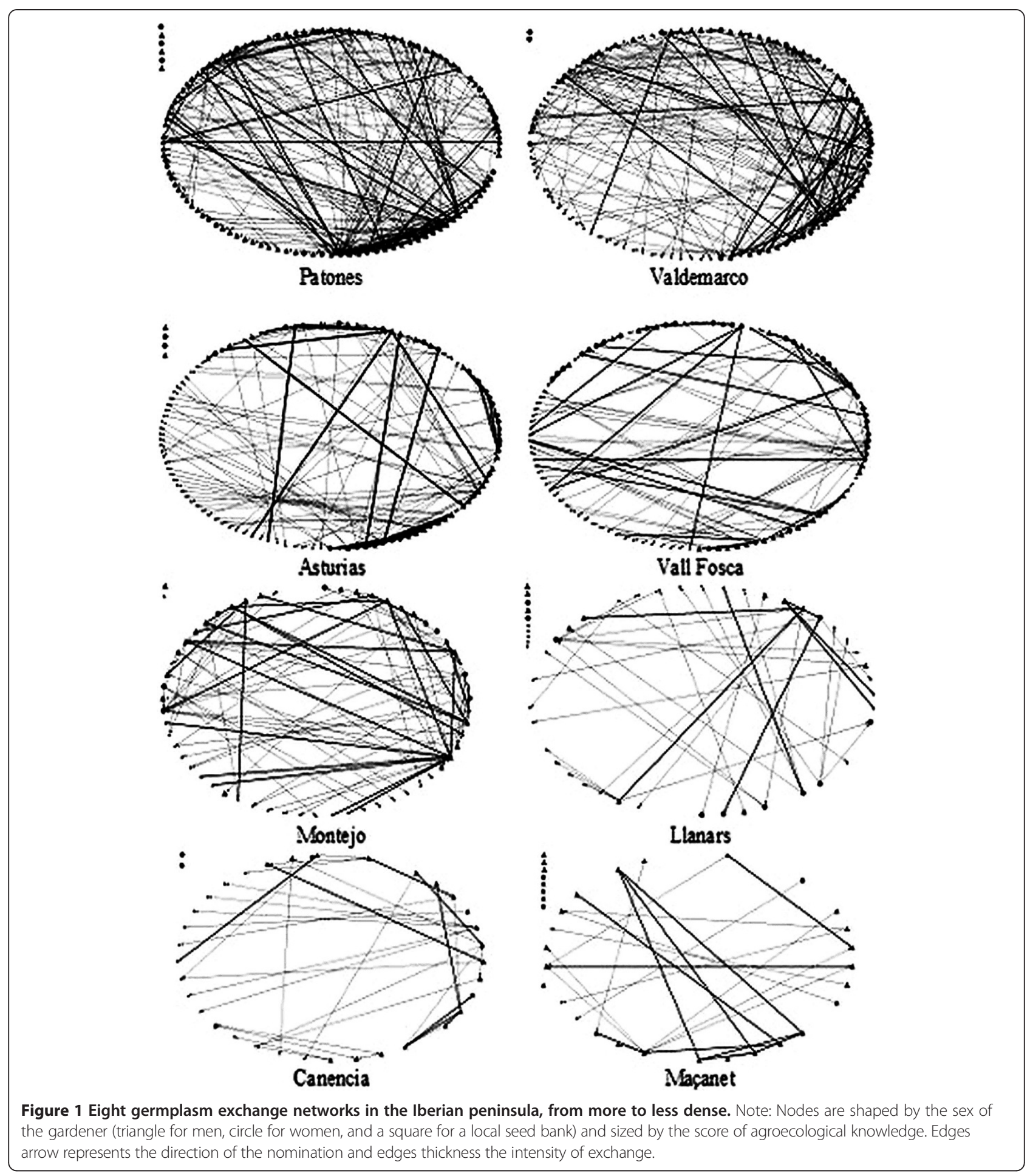

The average value for the variable broker was of 9.9, meaning that on average, each gardener connects 9.9 pairs of otherwise unconnected gardeners. As the previous variable, the variable broker displays large variation $(\mathrm{SD}=23.66)$, meaning that some gardeners had a much stronger centralizing role than others.
Results from Table 4 suggest a positive association between agroecological knowledge and one of our two centrality measures: broker. Thus, gardeners who connect more pairs of otherwise unconnected gardeners (i.e., higher value in the variable broker) have higher agroecological knowledge than people with a lower value in the variable 
Table 3 Definition and summary statistics of variables used in regressions

\begin{tabular}{|c|c|c|c|c|c|}
\hline Variable & Definition & $\mathbf{N}$ & Mean & & S.D. \\
\hline \multicolumn{6}{|c|}{ I. Outcome variable: } \\
\hline Agroecological knowledge & $\begin{array}{l}\text { Sum from scores on landraces knowledge and traditional } \\
\text { management practices (from } 0 \text { to 26) }\end{array}$ & 363 & 13.7 & & 5.37 \\
\hline \multicolumn{6}{|c|}{ II. Explanatory variables: } \\
\hline Degree & $\begin{array}{l}\text { Number of nominations given plus number of nominations } \\
\text { received by the person in the network of germplams } \\
\text { seed exchange }\end{array}$ & 363 & 4.77 & & 4.26 \\
\hline Broker & Number of pairs connected through ego & 363 & 9.9 & & 23.66 \\
\hline \multicolumn{6}{|c|}{ III. Control variables: } \\
\hline Age & Age of the person, in years & 363 & 66.1 & & 13.79 \\
\hline Male & $\begin{array}{l}\text { Dummy variable that captures the sex of the person } \\
\text { interviewed, } 1=\text { male, } 0=\text { female }\end{array}$ & 363 & 0.68 & & 0.46 \\
\hline Years gardening & Number of years the person has been gardening & 363 & 44.7 & & 24.26 \\
\hline \multirow[t]{2}{*}{ Egonetwork } & Size of the person's networks & 363 & 3.78 & & 3.38 \\
\hline & & $\mathbf{N}$ & \multicolumn{3}{|c|}{$\%$} \\
\hline \multirow[t]{4}{*}{ Schooling } & No schooling & 45 & \multicolumn{3}{|c|}{12.40} \\
\hline & Primary school & 176 & \multicolumn{3}{|c|}{48.48} \\
\hline & Between primary school and university degree & 117 & \multicolumn{3}{|c|}{32.23} \\
\hline & University degree & 25 & \multicolumn{3}{|c|}{6.89} \\
\hline \multirow[t]{5}{*}{ Years of residency } & Never been resident & 15 & \multicolumn{3}{|c|}{4.13} \\
\hline & Between 1 and 5 years & 8 & \multicolumn{3}{|c|}{2.20} \\
\hline & Between 5 and 10 years & 12 & \multicolumn{3}{|c|}{3.31} \\
\hline & More than 10 years & 127 & \multicolumn{3}{|c|}{34.99} \\
\hline & Always been resident & 201 & \multicolumn{3}{|c|}{55.37} \\
\hline
\end{tabular}

broker. The association is statistically significant at the $95 \%$ confidence interval. We do not find a statistically significant association between the degree of a person and his/her agroecological knowledge, which implies that the number of people with whom a gardener exchanges plant propagation material is not related in a statistically significant way to the person's agroecological knowledge.

We tested the robustness of the findings by running a set of variations of the model (Table 5). In our first two robustness models, we included additional control variables that might affect an individual's agroecological knowledge and her centrality in the exchange network. In model [2] we included migratory status as control, as migrants might have different cultural background, which might increase the cost of acquiring the local agroecological knowledge [25,44]. In model [3] we included participation on social organizations in the area as engagement in collective action institutions can facilitate access to information and foster germplasm exchanges [25]. Model [4] resembles the core model, except that we ran the regression with the option clustering, and the network of seed exchange designated as the clustering variable. This option relaxes the assumption that individual observations are independent and requires only independence across clusters. This procedure adjusts for the fact that networks are the social units where gardeners exchange planting material and provides robust (and more conservative) estimates of variance around regression parameters. In model [5] we excluded the variables for the village of residency of gardeners. In model [6], we rescaled the value of the knowledge variable to improve comparability in knowledge scores collected with different questionnaires. Specifically, we calculated the deviation from the mean, or Z-score, of our measure of agroecological knowledge for each of our 10 networks. The results from our robustness analysis mostly confirm two findings of the core model. First, the degree of a person was not associated with his/her level of agroecological knowledge. Second, the value of the variable broker bears a positive and statistically significant association with the level of agroecological knowledge of a person in all the models.

\section{Discussion}

Structure of germplasm exchange networks

The analyzed networks display three common factors: low density of interactions (indicating that there are few exchanges between the actors), fragmentation (meaning that the actors are joint in different disconnected groups), and decentralization (implying that there are 
Table 4 Multivariate Poisson regression: agroecological knowledge and centrality in the network of germplasm exchange $(n=363)$

\begin{tabular}{lc}
\hline & Agroecological knowledge \\
\hline Explanatory variables: & $0.004(0.009)$ \\
\hline Weighted degree (normalized) & $0.279^{* * *}(0.099)$ \\
Broker (normalized) & $-0.005(0.002)$ \\
\hline Control variables: & $-0.084^{* *}(0.035)$ \\
\hline Age & $0.007^{* * *}(0.001)$ \\
Male & $0.001(0.010)$ \\
Years gardening & \\
Network size & $-0.001(0.048)$ \\
Schooling (ref. category no education) & $-0.047(0.057)$ \\
Primary school & $-0.095(0.092)$ \\
More than primary but without university degree & \\
With university degree & \\
Residency duration (ref category, never lived) & $0.101(0.146)$ \\
Between 1 and 5 years & $0.240^{*}(0.131)$ \\
Between 5 and 10 years & $0.275^{* * *}(0.093)$ \\
More than 10 years & $0.320^{* * *}(0.093)$ \\
Always resident & 0.18 \\
\hline
\end{tabular}

Note: For definition of variables see Table 1 . Robust standard errors in parenthesis. * ${ }^{* *}$, and ${ }^{* *}$ significant at the $10 \%, 5 \%$ and $1 \%$ level. Regressions contain a set of dummy variables for the network of data collection and a constant (not shown).

not main actors that agglutinate the majority of exchanges). Low interaction density of germplasm exchange dovetails with research highlighting that, despite their importance for in situ agrobiodiversity conservation [19], exchanges are not the primary seed source. In previous research [21], it has been reported that the primary propagules sources for most crops were from the farmer's own harvest and the market place. Our own previous research suggests the same pattern in the area. Thus, in Sierra Norte, $45 \%$ of the propagules are from commercial origin and 32\% from the own farmer [33]. So, a potential explanation of the low density of exchange of germplasm in our study areas lays in the presence of a formal seed supply system and in the prevalence of commercial varieties. In the study sites seed saving has increasingly been restricted to a smaller number of crops not available in the market. Several of our oldest informants mentioned that seed saving and exchanging was more common in the past, when there were no markets for seeds, but as seeds and plantlets for most varieties are conveniently available at the local markets, the number of exchanges has decreased. The extra work required to prepare the seedbed and the degeneration of seeds are disincentives to maintain a local seed system [30]. Gardeners continue to share the saved seeds for few crops not available in the market and with some cultural value (such as landraces), but they are less inclined to share seeds obtained in the market, as they expect other gardeners to also obtain those seeds through the market.

Table 5 Robustness analysis

\begin{tabular}{|c|c|c|c|}
\hline \multicolumn{2}{|c|}{ Changes: } & \multirow{2}{*}{$\frac{\text { Degree }}{0.004(0.009)}$} & \multirow{2}{*}{$\begin{array}{c}\text { Broker } \\
0.279^{* * *}(0.099)\end{array}$} \\
\hline [1] & Core model (as in Table 3) & & \\
\hline [2] & Controlling for the migratory status of the person & $0.003(0.009)$ & $0.287^{* * *}(0.101)$ \\
\hline [3] & Controlling for participation in organizations & $0.001(0.009)$ & $0.300^{* * *}(0.099)$ \\
\hline [4] & Clustering by seed exchange networks & $0.004(0.012)$ & $0.279 *(0.171)$ \\
\hline [5] & Excluding dummies for village of residency & $0.005(0.009)$ & $0.230^{* *}(0.096)$ \\
\hline [6] & Using Z-score value for agroecological knowledge score (and Ordinary Least Square regression model) & $0.025(0.024)$ & $0.737^{* *}(0.316)$ \\
\hline
\end{tabular}

Note: Regressions resemble the model in Table 3, except for the changes specified in the column "Changes". Robust standard errors in parenthesis. * **, and *** significant at the $10 \%, 5 \%$ and $1 \%$ level. 
Low density of exchanges probably relates to the second commonality of the networks studied, fragmentation, although fragmentation does not fully explain low density. Our ethnographic understanding suggests that, in addition to low density, two more factors might help explain fragmentation: social distance between gardeners and physical distance between gardens. Researchers have highlighted that cultural distance between farmers (i.e., linguistic differences) prevent germplasm exchanges by increasing the costs of acquiring information [25,44,45]. Similarly, in our study areas, sociocultural differences between elderly who have traditionally lived in the areas and young migrants recently settled might help explain fragmentation in germplasm exchange networks. We have observed that the agricultural practices and crop preferences of the two groups often differ, preventing exchanges between those groups and thus contributing to network fragmentation. Additionally, we have also observed that in those areas where gardens are physically separated (i.e., Llanars, Llançà, Maçanet de Cabrenys, Molló in the Catalan Pyrenees), there are less exchanges than in those areas where gardens are closer to each other (i.e., Montejo de la Sierra or Valdemanco), the exception being the two valleys in our sample (Vall Fosca and Valle del Cordal), where -despite distance between gardens- there is not a high degree of fragmentation.

A third commonality between the networks analyzed is their low level of centralization. None of the networks in our sample includes a gardener or a group of them centralizing the exchange of seeds, not even in the case where one of the actors is a local seed bank (see [30] for a thorough analysis). Rather, germplasm seems to freely flow across the different gardeners who compose a subnetwork or component. A decentralized system of germplasm exchange could make networks of germplasm exchange more resilient to failures of a specific gardener (i.e., death, migration), since each gardener could potentially access multiple sources of germplasm providers $[46,47]$. This property, however, is conditional to the fact that the flows between gardeners are sufficient, timely, and accessible enough to re-stock seed lots if there were a loss.

We also found an important difference in the structure of the networks analyzed in relation to the presence of external links: in four of the 10 networks all the exchanges occurred among gardeners within the village, whereas in the other six networks there is an important prevalence of seed acquisition from individuals and organizations outside the village. We do not have a clear explanation for the differences found in our sample, although we think they might relate to the number of temporary and permanent migrants in each case study. For example, with the exception of Canencia, communities in the Sierra Norte, have several external actors. This is also the case in Asturias. In fact, many of the residents of those communities commute every day for work, or live in one community but have their gardens in another one. Those movements allow for fluid relations with people outside the studied network. In contrast, gardens in the Catalan Pyrenees (except in Vall Fosca) are mostly managed by elders who do not have the same social mobility than in the previous case, and who might -consequently have less external links. This characteristic of the networks could have implications on the overall network diversity as previous work suggests that plant propagation material acquired from the community is mostly oriented to regular supply of seeds, whereas the acquisition of germplasm from outside the community contributes to the introduction of new diversity $[24,28,48]$ as the presence of external links might provide more choices.

\section{Agroecological knowledge and centrality}

We now turn the discussion to the second significant finding of this paper: the association between a person's centrality in the germplasm exchange network and his/ her level of agroecological knowledge.

One of the two centrality measures tested, broker, bear a positive and statistically significant association with a person's level of agroecological knowledge. This association easily finds explanation on previous literature. On the one side, the social network literature has also highlighted the preferential access to information for central actors in a network [12]. In his seminal work, Burt [49] borrowed the term tertius gaudens ("rejoicing third") from the German sociologist Simmel to emphasize the ability of the tertius to pass accurate, ambiguous, or distorted information between otherwise unconnected nodes, thus highlighting the role of brokers in information exchange. On the other side, the germplasm exchange network literature has highlighted that seeds are not exchanged in a cultural vacuum; rather seeds often circulate accompanied with information related to their qualities and to particular management practices [25,50,51], which suggest an overlap in the network of seeds and information exchange. As we have seen in the field, germplasm exchange is always accompanied by detailed information about how to grow, care, and use the exchanged crop. Furthermore, we have often observed follow up questioning about the success of the exchanged crop, a situation that is used to reinforce the information given at the moment of exchange, or to add new information on the exchanged variety, or of gardening in general. Thus, because the physical exchange of germplasm contributes to create and strengthen social links, it is not surprising that we find a positive association between the position of a person on the network of germplasm exchanges and her level of agroecological knowledge. 
But then, why only one of our two measures of centrality (i.e., brokers) is associated with agroecological knowledge? Why does not the variable weighted degree bear the same association? Knowledge is generated and transmitted through a complex process that includes more than two nodes (in our case, people who exchange seeds). Differently from the measure degree that captures the number of direct contacts between people, the measure "broker" also captures the person's ability for bridging structural holes. Considering that planting material often flows with associated knowledge, people with a higher centrality, as measured by the variable broker, might hold a structural position that allows them to gain access to many pieces of group specific information (i.e., information shared by elders permanently living in the area, information brought by young newcomers, or information from clusters outside the village). Contrary, people with a large number of direct links, but not so well connected in the overall structure of the network, might be less aware of different alternatives. Access to preferential information across groups help explain the positive association between the measure broker in the network of germplasm exchange and our measure of agroecological knowledge.

\section{Conclusion}

We conclude highlighting a theoretical and a policy implication of our study. At a theoretical level, our study emphasizes the role of the structural position of a person in a network in explaining intracultural variation on levels of traditional ecological knowledge. As other type of information, traditional ecological knowledge is embedded in social networks and may only be apparent in the context of relations and interactions. The finding that the centrality of an individual in a network helps explaining her/his level of traditional ecological knowledge highlights the importance of social relations in the construction of traditional ecological knowledge.

Our study has also a policy implication. Researchers have noticed the link between exchange of germplasm and in situ agrobiodiversity conservation [26,27,52], but have rarely studied the structure of the networks where those exchanges happen. Understanding the characteristics of germplasm exchange networks might help in the design of policies to sustain in situ agrobiodiversity. For example, our results suggest that, the studied networks display some common structural characteristics that could reduce the flow of planting material: low density of exchanges and network fragmentation. Taken together, the two characteristics imply that there are large proportions of gardeners that can not reach one to each other, thus reducing the number of possible exchanges. The networks also displayed some characteristics that -under certain circumstances- could enhance the flow of planting material: low centralization and the presence of external links. Policies that aim at sustaining in situ agrobiodiversity by increasing exchanges of planting material should focus on increasing the density of exchanges within the existing networks and on bridging relations between unconnected subgroups.

\section{Competing interests}

The authors declare that they have no competing interests.

\section{Authors' contributions}

LC-M, LA-M, TG, JL, RO, MP, MP-S, MR and JV participated in the design of the study and in data collection. VR-G, JM, LC-M, carried out the statistical analysis. TG and VR-G coordinated the study. VR-G wrote the first draft of the manuscript. All authors read and approved the final manuscript.

\section{Acknowledgements}

Research was funded by the Programa de Ciencias Sociales y Humanidades del Ministerio de Educación y Ciencia (Spain) (SEJ2007-60873/SOCl and CSO2011-27565). We thank all the gardeners who collaborated in the project. Thanks also go to Isabel Angosto, Sara Vila and Alexandra Jesch for help during data collection and Resilient Dry Land Systems, ICRISAT-Patancheru for providing office facilities to Reyes-García.

\section{Author details}

${ }^{1}$ ICREA and Institut de Ciència i Tecnologia Ambientals, Universitat Autònoma de Barcelona, 08193 Bellaterra, Barcelona, Spain. ²Departament d'Antropologia, Universitat Autònoma de Barcelona, 08193 Bellaterra, Barcelona, Spain. ${ }^{3}$ Institut de Ciència i Tecnologia Ambientals, Universitat Autònoma de Barcelona, 08193 Bellatera, Barcelona, Spain. ${ }^{4}$ Departamento de Biología (Botánica), Universidad Autónoma de Madrid, C/ Darwin 2. Campus de Cantoblanco, 28049, Madrid, Spain. ${ }^{5}$ Departamento de Biología de Organismos y Sistemas, Universidad de Oviedo. Campus del Cristo, 33071, Oviedo, Spain. 'Laboratori de Botànica, Facultat de Farmàcia, Universitat de Barcelona, Av. Joan XXIII, s.n, 08028, Barcelona, Catalonia, Spain. ${ }^{7}$ Institut Botànic de Barcelona (IBB-CSIC-ICUB), Passeig del Migdia S.n., Parc de Montjuïc, 08038, Barcelona, Catalonia, Spain

Received: 25 March 2013 Accepted: 22 July 2013

Published: 24 July 2013

\section{References}

1. Ghimere SK, McKey D, Aumeeruddy-Thomas Y: Heterogeneity in Ethnoecological Knowledge and Management of Medicinal Plants in the Himalayas of Nepal: Implications for Conservation. Ecol Soc 2004, 9:6.

2. Hunn ES, Johnson DR, Russell PN, Thornton TF: Huna Tlingit Traditional Environmental Knowledge, Conservation, and the Management of a "Wilderness" Park. Curr Anthropol 2003, 44:S79-S103.

3. Becker CD, Ghimire K: Synergy between traditional ecological knowledge and conservation science supports forest preservation in Ecuador. Conserv Ecol 2003, 8(1):1.

4. Moller H, Berkes F, Lyver PO, Kislalioglu M: Combining science and traditional ecological knowledge: Monitoring Populations for comanagement. Ecol Soc 2004, 9(3):7.

5. Folke C: Traditional knowledge in social-ecological systems. Ecol Soc 2004 9(3):7.

6. Berkes F, Colding J, Folke C: Rediscovery of traditional ecological knowledge as adaptive management. Ecol Appl 2000, 10:1251-1262.

7. Boster JS: Exchange of varieties and information between Aguaruna manioc cultivators. Am Anthropol 1986, 88:429-436.

8. Camou-Guerrero A, Reyes-García V, Martinez-Ramos M, Casas A: Knowledge and use value of plant species in a raramuri community: A gender perspective for conservation. Hum Ecol 2008, 36:259-272.

9. Reyes-García V, Vadez V, Byron E, Apaza L, Leonard WR, Perez E, Wilkie D: Market economy and the loss of folk knowledge of plant uses: Estimates from the Tsimane' of the Bolivian Amazon. Curr Anthropol 2005, 46:651-656.

10. Sternberg R, Nokes C, Geissler P, Prince R, Okatcha F, Bundy D, Grigorenko E: The relationship between academic and practical intelligence: a case study in Kenya. Intelligence 2001, 29:401-418.

11. Cavalli-Sforza LL, Feldman MW, Chen KH, Dornbusch SM: Theory and Observation in Cultural Transmission. Science 1982, 218:19-27. 
12. Burt RS: Structural holes and good ideas. Am J Sociol 2004, 110:349-399.

13. Rogers EM: Diffusion of innovations. New York: The Free Press; 1962.

14. Valente TW: Network Models of the Diffusion of Innovations. California: Cresskill NJ Hampton Press; 2005.

15. Brass DJ, Burkhardt ME: Centrality and Power in organizations. In Networks and Organizations. Edited by Nohria E. Boston MA: Harvard University Press; 1992:191-215.

16. Ramirez-Sanchez S, Pinkerton E: The Impact of Resource Scarcity on Bonding and Bridging Social Capital: the Case of Fishers' Information-Sharing Networks in Loreto, BCS, Mexico. Ecol Soc 2009, 14(1):22

17. Crona B, Bodin O: What you know is who you know? Communication patterns among resource users as a prerequisite for co-management. Ecol Soc 2006, $11(2): 7$

18. Atran S, Medin D, Ross N, Lynch E, Vapnarsky V, Ucan Ek E, Coley J, Timura C, Baran M: Folkecology, Cultural epidemiology, and the Spirit of the Commons. A Garden Experiment in the Maya Lowlands, 1991-2001. Curr Anthropol 2002, 43:421-451.

19. Coomes OT: Of Stakes, Stems, and Cuttings: The Importance of Local Seed Systems in Traditional Amazonian Societies. Prof Geogr 2010, 62:323-334

20. Acosta-Naranjo R, Diaz-Diego J: Y en sus manos la vida. Los cultivadores de las variedades locales de Tentudía. Centro de Desarrollo Comarcal de Tentudía: Tentudía, Extremadura; 2008

21. Winters P, Cavatassi R, Lipper L: Sowing the Seeds of Social Relations: The Role of Social Capital in Crop Diversity. In Book Sowing the Seeds of Social Relations: The Role of Social Capital in Crop Diversity. Edited by vol. ESA Working Paper No. 06-16. City: Agricultural and Development Economics Division (ESA). Italy: The Food and Agriculture Organization; 2006.

22. Armitage DR: Traditional agroecological knowledge, adaptive management and the socio-politics of conservation in Central Sulawesi, Indonesia. Environ Conserv 2003, 30:79-90

23. Calvet-Mir L, Calvet-Mir M, Vaqué-Nunez L, Reyes-García V: Landraces in situ Conservation: A Case Study in High-Mountain Home Gardens in Vall Fosca, Catalan Pyrenees, Iberian Peninsula. Econ Bot 2011 65:146-157.

24. Almekinders $\mathrm{C}$, Louwaars $\mathrm{N}$, Brujin $\mathrm{GH}$ : Local seed systems and their importance for an improved seed supply in developing countries. Euphytica 1994, 78:207-216.

25. Badstue LB, Bellon MR, Berthaud J, Ramirez A, Flores D, Juarez X: The dynamics of farmers' maize seed supply practices in the Central Valleys of Oaxaca, Mexico. World Dev 2007, 35:1579-1593.

26. Ban N, Coomes OT: Home gardens in Amazonian Peru: diversity and exchange of planting material. Geogr Rev 2004, 94:348-367.

27. Bellon MR: Conceptualizing Interventions to Support On-Farm Genetic Resource Conservation. World Dev 2004, 32:159-172

28. Zimmerer KS: Geographies of seed networks for food plants (potato, ulluco) and approaches to agrobiodiversity conservation in the Andean countries. Soc Nat Resour 2003, 16:583-601.

29. Ellen R, Platten S: The social life of seeds: the role of networks of relationships in the dispersal and cultural selection of plant germplasm. J R Anthropol Inst 2011, 17:563-584.

30. Calvet-Mir L, Calvet-Mir M, Molina JL, Reyes-García V: Seeds exchange as an agrobiodiversity conservation mechanism: A case study in Vall Fosca, Catalan Pyrenees, Iberian Peninsula. Ecol Soc 2012, 17(1):29.

31. Hopkins AL: Medicinal plant remedy knowledge and social networks in Tabi, Yucatan. Mexico: University of Florida; 2009.

32. Naredo JM: La evolución de la agricultura en España (1940-2000). Granada: Editorial Universidad de Granada; 2004.

33. Aceituno-Mata L: Estudio etnobotánico y agroecológico de la Sierra Norte de Madrid. Madrid: Universidad Autónoma de Madrid; 2010.

34. Rigat $M$, Garnatje T, Vallès J: Plant biodiversity in Pyrenean homegardens (Catalonia, Iberian peninsula): current state of a mountain agroecosystem. Acta Botanica Gallica 2011, 158:525-551.

35. Calvet-Mir L, Gómez-Bagetthun E, Reyes-García V: Beyond food production: Ecosystem services provided by home gardens. A case study in Vall Fosca, Catalan Pyrenees, northeastern Spain. Ecol Econ 2012, 74:153-160

36. Reyes-García V, Aceituno L, Vila S, Calvet-Mir L, Garnatje T, Jesch A, Lastra JJ, Parada M, Rigat M, Vallès J, Pardo-de-Santayana M: Home gardens in three mountain regions of the Iberian Peninsula: description, motivation for gardening, and gross financial benefits. J Sustain Agric 2012, 36:249-270.
37. Parada $\mathrm{M}$, Carrió $\mathrm{E}$, Bonet MA, Vallès J: Ethnobotany of the Alt Empordà region (Catalonia, Iberian Peninsula) Plants used in human traditional medicine. J Ethnopharmacol 2009, 124:609-618.

38. Davis A, Wagner JR: Who knows? On the importance of identifying "Experts" when researching local ecological knowledge. Hum Ecol 2003, 31:463-489.

39. Marsden PV: Network data and measurement. Annu Rev Sociol 1990, $16: 435-463$

40. Freeman LC: The development of social network analysis: a study in the sociology of science. Vancouver, British Columbia, Canada: Empirical Press; 2004

41. Scott J: Social network analysis: a handbook. Newberry Park, California, USA Sage Publications; 2000.

42. Wasserman S, Faust K: Social Network Analysis. Methods and Applications. Cambridge: Cambridge University Press; 1994.

43. Borgatti SP, Everett MG, Freeman LC: Ucinet6 for Windows. Software for Social Network Analysis. In Book Ucinet6 for Windows. Software for Social Network Analysis. Edited by Analytic Technologies; 2002.

44. Perales HR, Benz BF, Brush SB: Maize diversity and ethnolinguistic diversity in Chiapas, Mexico. Proc Natl Acad Sci USA 2005, 102:949-954.

45. Benz B, Perales H, Brush S: Tzeltal and Tzotzil farmer knowledge and maize diversity in Chiapas, Mexico. Curr Anthropol 2007, 48:289-300.

46. Abrahamson E, Rosenkopf L: Social network effects on the extent of innovation diffusion: a computer simulation. Organ Sci 1997, 8:289-309.

47. Weimann G: On the importance of marginality: one more step into the two-step flow of communication. Am Sociol Rev 1982, 47:764-773.

48. McGuire SJ: Securing access to seed: Social relations and sorghum seed exchange in eastern Ethiopia. Hum Ecol 2008, 36:217-229.

49. Burt RS: Structural Holes: The Social Structure of Competition. Harvard: Harvard University Press; 1992.

50. Keleman A, Hellin J, Bellon MR: Maize diversity, rural development policy, and farmers' practices: lessons from Chiapas, Mexico. Geogr J 2009, 175:52-70.

51. Kiptot E, Franzel S, Hebinck P, Richards P: Sharing seed and knowledge: farmer to farmer dissemination of agroforestry technologies in western Kenya. Agrofor Syst 2006, 68:167-179.

52. Zimmerer KS: Changing fortunes: Biodiversity and peasant livelihood in the Peruvian Andes. Berkeley: University of California Press; 1996.

doi:10.1186/1746-4269-9-53

Cite this article as: Reyes-García et al:: "Tertius gaudens": germplasm exchange networks and agroecological knowledge among home gardeners in the Iberian Peninsula. Journal of Ethnobiology and Ethnomedicine 2013 9:53.

\section{Submit your next manuscript to BioMed Central and take full advantage of:}

- Convenient online submission

- Thorough peer review

- No space constraints or color figure charges

- Immediate publication on acceptance

- Inclusion in PubMed, CAS, Scopus and Google Scholar

- Research which is freely available for redistribution

Submit your manuscript at www.biomedcentral.com/submit
C Biomed Central 